\title{
A Portfolio Theory Approach to Fishery Management
}

\author{
Marius Rădulescu ${ }^{1}$, Constanța Zoie Rădulescu ${ }^{2}$, Magdalena Turek Rahoveanu ${ }^{3}$, Gheorghiță Zbăganu ${ }^{4}$ \\ ${ }^{1}$ Institute of Mathematical Statistics and Applied Mathematics, \\ Casa Academiei Române, Calea 13 Septembrie nr.13, Bucharest 5, RO-050711, ROMANIA, \\ mradulescu@csm.ro \\ 2 National Institute for Research and Development in Informatics, \\ 8-10 Averescu Avenue, Bucharest 1, RO-011455, ROMANIA, \\ radulescu@ici.ro \\ ${ }^{3}$ Institute for Agricultural Economics and Rural Development, \\ Bd. Măraşti nr. 61, Bucharest 1, RO-011464, ROMANIA, \\ mturek2003@yahoo.com \\ ${ }^{4}$ Faculty of Mathematics and Computer Science, University of Bucharest, \\ Academiei 14, Bucharest, RO-010014, ROMANIA, \\ zbagang@fmi.unibuc.ro
}

Abstract: Several portfolio selection models for fishery management are presented. The financial risk is measured by the first lower partial moment of the return. The purpose of the models is to obtain optimal fishing plans that minimize the financial risk or maximize the expected return. The ranges of variation for the parameters of the minimum risk model are determined. A numerical example for a fishery from the Galati county, Romania is analyzed.

Keywords: portfolio selection, fishery management, lower partial moment, risk, maximum sustainable yield, risk.

\section{Introduction}

In the last decades fisheries management has been shifting toward an ecosystem-based fisheries management, also called an ecosystem approach to fisheries. The ecosystem approach to fishery management is a significant step towards sustainable use of the natural resources. It combines harmoniously economic objectives with environmental and social objectives. In this paper, we present several portfolio selection models for fishery management. Our fishery models consider multiple fish species and take into account both economic and environmental constraints. They are inspired from Sanchirico's paper [29] and take into account the ecosystem approach. Note that the approach based on financial portfolio theory to fish management is compatible with the ecosystem-based approach. The differences between our model and the Sanchirico portfolio selection model from Sanchirico [29] are the following:

- in our models an additional constraint connected to the budget for fish harvesting or with the input costs is introduced;

- we determine the range of variation for the parameters of our models. This facilitates the integration of our models in a decision support system;
- we use the first lower partial moment as a measure for the financial risk. This approach implies the introduction of a target parameter for the return of the fishing plans. The financial risk occurs if the return of the fishing plan is below this target parameter.

An approach for managing discrete assets based on the first lower partial moment can be found in Radulescu [24].

\section{The Portfolio Approach to Multi-species Management of Fish Stocks}

According Edwards et al. [9] and [10], a portfolio framework for fishery management is a technical methodology that systematically combines fish stocks that are joined by ecology (e.g., predation, competition) and unspecialized fishing technologies (e.g., mixed-species trawls) into a portfolio which balances expected aggregate returns against the risks associated with stock-attribute and other uncertainties.

The portfolio approach to multi-species management of fish stocks supposes that:

- fish stocks are real assets capable of generating a flow of returns indefinitely; 
- society's objectives and constraints are clearly defined and capable of being evaluated;

- the combinations of stock sizes and other attributes for each species are evaluated for their effects on aggregate returns;

- there exists a tradeoff between the expected aggregate returns and risk (i.e., variation in returns).

In general, portfolios are used to find the most desirable combination of assets given their individual value and risk properties. Financial securities and real capital portfolios can be designed to ma-nage risk by balancing the mix of assets. In contrast to selecting financial securities from independent companies or governments, fish stocks which have co-evolved over many years and are harvested, in many cases, by unspecialized technologies in mixed species. Fisheries should be managed jointly due to spillover interactions between them in order to optimize their overall value. That is, harvesting one species generally has important implications for other species.

Fish populations are real assets belonging to society. They are capital stocks that can potentially yield benefits indefinitely to the owners of stock rights (governments, commons, or private individuals) and the public. From an economics standpoint, the value of a renewable asset, such as a fish stock, is the present value of income (revenues minus costs) from future harvests, appropriately discounted and balanced against the income from current harvest (a dividend).

The economic value of a fish stock is a function of current and future prices and extraction costs, and is subject to production technology and the resource growth rate Fisher [12].

Prices are derived from people's demand (preferences) for seafood and other commodities and services. Fish market prices are influenced by product attributes, such as species and fish size. Extraction costs are determined by market prices for inputs, such as fuel and insurance, and by extraction technology and stock attributes. Other costs are associated with administration, management, and enforcement (i.e., transaction costs).
Ecological and technological interactions are sufficient reasons to manage multi-species fish stocks for their aggregate benefits because stocks affect each others' dynamics. Harvesting one species can affect the stock sizes and capitalized values of many other species in the community. There are three distinct classes of risk that affect fishery returns: availability of fish, market price, and institutions Pontecorvo [20].

\section{Application of Financial Portfolio Theory to Fishery Management}

An important mathematical instrument which was successfully applied to modelling the problems from fisheries management is portfolio theory. The above mentioned theory was developed as a result of the research in the domain of financial management. Its aim is the elaboration of a quantitative analysis of how investors can diversify their portfolio in order to minimize risk and maximize returns. The theory was introduced in 1952 by University of Chicago economics student Harry Markowitz, who published his doctoral thesis, "Portfolio Selection" in the Journal of Finance, Markowitz [18]. There exist many applications of portfolio theory to domains that do not imply finance such as agriculture Blandon [7], Blank [8], Romero [27], [28], Radulescu [22], sire selection Schneeberger [30], biodiversity, Figge [11], Koellner and Schmitz [16], energy Bazilian and Roques [5], sustainable production planning Radulescu [23] and [25] etc. For supplementary references regarding applications of portfolio theory to nonfinancial areas see Radulescu [21]. The application of portfolio theory for finding an optimal harvesting portfolio is popular in the literature. Managing fish stocks in terms of a portfolio of economic assets is likely to significantly increase benefits for society relative to single-species approaches. Fishery portfolio selection models for fishery management were formulated and analyzed in Hatch and Atwood [14], Sanchirico [29], Sethi [31]. In Sanchirico [29] the authors adapt financial portfolio theory as a method for ecosystem-based fishery management that accounts for species interdependencies, uncertainty, and sustainability constraints. 
They illustrate their method with routinely collected data available from the Chesapeake Bay and demonstrate the gains from taking into account variances and covariances of gross fishing revenues in setting species total allowable catches.

In Larkin [17] the authors embed a portfolio decision framework into a multi-period bioeconomic model in order to quantify the riskbenefit tradeoffs of alternative strategies. They develop alternative sets of processed seafood products for managing the risks that occur as a result of harvests from commercial fish stocks. The model is used to generate an efficient portfolio frontier to estimate possible rent dissipation from status quo management. Frontiers are also generated for seafood processors and brokers. The authors discuss implications for the different industry agents.

Drawing the analogy between managing risky assets and managing multispecies fisheries is a relatively new idea, even though the foundation for this idea is neither new to ecology nor economics. In ecology, Walters [32] derives a mean-variance frontier for singlespecies management, while Real [26] uses portfolio theory to describe animal behaviour.

Portfolio management of fisheries can be a means of allocating catch across life history stages. Baldursson and Magnusson [4], Arnason [2] alludes to multispecies portfolio management in a deterministic bioeconomic model by suggesting that managers choose a vector of Total Allowable Catches (TACs), while Hanna [13] explicitly discusses the idea of selecting "species portfolios" as a means to match management objectives with ecosystem structure. Hilborn et al. provides in [15] a justification for portfolio management at the regional level by pointing out that total productivity aggregated across species is subject to less variability than the productivity of individual species. Edwards et al. formally develop in [9] the analogy within the context of standard bio-economic models and provide a stylized simulation of a threespecies system. More recently, Perusso at al. apply portfolio theory in [19] to individual fishermen targeting decisions in the U.S. Atlantic and Gulf of Mexico pelagic longline fishery. An interesting survey on the application of portfolio theory to fisheries management may be found in Yang [33].
Several references on applications of operations research to fish management can be found in Arnason [3] and Bjørndal [6].

\section{Portfolio Selection Models for Fisheries Management}

In this section we shall present a multiobjective programming model for fisheries management. Starting from it we define several single objective programming problems: a minimum risk problem, a maximum expected return problem and an optimal trade-ff problem. In order to facilitate the use of these models in a decision support system we gave procedures for finding the ranges of variation for the parameters.

Suppose that we have $\mathrm{n}$ fish species $S_{1}, S_{2}, \ldots, S_{n}$. Denote by $\xi_{i}$ the market price of one $\mathrm{kg}$ of fish of species $S_{i}$. Of course all $\xi_{i}$ are random variables. Let $\xi=\left(\xi_{1}, \xi_{2}, \ldots, \xi_{n}\right)$ denote the random vector of returns. Denote by $\mu_{i}$ the mean of $\xi_{i}$. Let $\boldsymbol{\mu}=\left(\mu_{1}, \mu_{2}, \ldots, \mu_{n}\right)$. Denote by $b_{i}$ the cost associated to fishing one $\mathrm{kg}$ of fish (or the cost of inputs for producing one $\mathrm{kg}$ of fish) from species $S_{i}$ and with $a_{i}$ the maximum sustainable yield for the fish of species $S_{i}$. Let $\mathbf{a}=\left(a_{1}, a_{2}, \ldots, a_{n}\right), \mathbf{b}=\left(b_{1}, b_{2}, \ldots, b_{n}\right)$. Let $x_{i}$ be the quantity harvested from fish of species $S_{i}$. Of course $x_{i} \geq 0$ for every $\mathrm{i}=1,2, \ldots, \mathrm{n}$. The vector $\mathbf{x}=\left(x_{1}, x_{2}, \ldots, x_{n}\right)$ will be called a portfolio. The cost of harvesting a portfolio $\mathrm{x}$ is equal to $\sum_{i=1}^{n} b_{i} x_{i}=\mathbf{b}^{\mathrm{T}} \mathbf{x}$. The return (resp. the expected return) from harvesting a portfolio $\mathbf{x}$ is equal to $\sum_{i=1}^{n} \xi_{i} x_{i}=\xi^{\mathrm{T}} \mathbf{x}$ (resp. to $\left.\sum_{i=1}^{n} \mu_{i} x_{i}=\boldsymbol{\mu}^{\mathrm{T}} \mathbf{x}\right)$.

In reality the vectors $\xi=\left(\xi_{1}, \xi_{2}, \ldots, \xi_{n}\right)$ and $\boldsymbol{\mu}=\left(\mu_{1}, \mu_{2}, \ldots, \mu_{n}\right)$ depend on time. Fishing and pollution are important factors that make that the above mentioned vectors vary along the time. The financial risk of the portfolio $\mathbf{x}$ may be defined in several ways.

One traditional way is to define the risk as the variance of the return $f_{1}(\mathbf{x})=\operatorname{Var}\left(\xi^{\mathrm{T}} \mathbf{x}\right)=\mathbf{x}^{\mathrm{T}} \mathbf{C} \mathbf{x}$. 
If $t$ is a real number we shall denote by $t_{+}$the positive part of $t$, that is:

$t_{+}=\max (t, 0)=\frac{t+|t|}{2}$

Alternative ways to define the risk are $f_{2}(\mathbf{x})=E\left[\left(\tau-\xi^{\mathrm{T}} \mathbf{x}\right)_{+}\right], f_{3}(\mathbf{x})=P\left(\xi^{\mathrm{T}} \mathbf{x}<\tau\right)$.

A general problem in the fisheries management is the following multiobjective problem

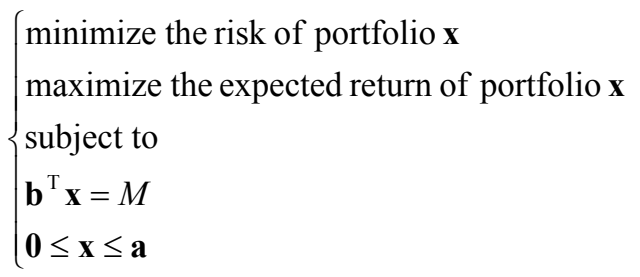

Starting from the above multi-objective problem one can formulate the following single objective problems: the minimum risk problem, the maximum expected return problem, the optimal trade-off problem.

In this paper we shall use as a measure of financial risk the map $f_{2}(\mathbf{x})=E\left[\left(\tau-\xi^{\mathrm{T}} \mathbf{x}\right)_{+}\right]$. This risk measure is called the first partial lower moment of the return.

\section{The minimum risk problem}

In the frame of this problem the decision maker looks for a portfolio $\mathbf{x}=\left(x_{1}, x_{2}, \ldots, x_{n}\right)$ that minimizes the financial risk and satisfies the following constraints: the expected return is greater than a given limit $W$ and the sum invested in the portfolio of fish is equal to $M$. One can easily see that the risk occurs when the return is smaller than the target $\tau$.

$\left(\mathrm{P}_{1}\right)$

$$
\left\{\begin{array}{l}
\min E\left[\left(\tau-\xi^{\mathrm{T}} \mathbf{x}\right)_{+}\right] \\
\boldsymbol{\mu}^{\mathrm{T}} \mathbf{x} \geq W \\
\mathbf{b}^{\mathrm{T}} \mathbf{x}=M \\
\mathbf{0} \leq \mathbf{x} \leq \mathbf{a}
\end{array}\right.
$$

From the last two constraints one can easily see that $\mathbf{0} \leq M \leq \mathbf{b}^{\mathrm{T}} \mathbf{a}$.

Denote by $r_{t i}$ the market price of one $\mathrm{kg}$ of fish of species $S_{i}$ at moment $t$. Suppose that there are $m$ moments of time, that is $t \in\{1,2, \ldots, m\} . \quad$ Consider the vectors $\mathbf{r}_{t}=\left(r_{t 1}, r_{t 2}, \ldots, r_{t n}\right), t \in\{1,2, \ldots, m\}$ and the matrix $\mathbf{R}=\left(r_{t i}\right) . \quad$ For $\quad$ every $\quad i \in\{1,2, \ldots, n\}$ denote $v_{i}=\frac{1}{m} \sum_{t=1}^{m} r_{t i}$ and $\mathbf{v}=\left(v_{1}, v_{2}, \ldots, v_{n}\right)$. Note that $\frac{1}{m} \sum_{t=1}^{m}\left(\tau-\mathbf{r}_{t}^{T} \mathbf{x}\right)_{+}$is an estimation of the risk function $E\left[\left(\tau-\xi^{\mathrm{T}} \mathbf{x}\right)_{+}\right]$and $\mathbf{v}=\left(v_{1}, v_{2}, \ldots, v_{n}\right)$ is an estimation of the vector $\boldsymbol{\mu}=\left(\mu_{1}, \mu_{2}, \ldots, \mu_{n}\right)$. Consider the problem

$$
\left(P_{1}^{\prime}\right)\left\{\begin{array}{l}
\min \left[\frac{1}{m} \sum_{t=1}^{m}\left(\tau-\mathbf{r}_{t}^{T} \mathbf{x}\right)_{+}\right] \\
\mathbf{v}^{\mathrm{T}} \mathbf{x} \geq W \\
\mathbf{b}^{\mathrm{T}} \mathbf{x}=M \\
\mathbf{0} \leq \mathbf{x} \leq \mathbf{a}
\end{array}\right.
$$

One can easily see that the problem $\left(P_{1}^{\prime}\right)$ is the problem $\left(\mathrm{P}_{1}\right)$ where the risk function and the expected return are replaced with estimation of them. From now on we shall focus our attention on the problem $\left(P_{1}^{\prime}\right)$.

An important problem is to find the range of the parameter $W$. In order to find the limits of this range we shall solve the following problems

(Wmin) $\min \left\{\mathbf{v}^{\mathrm{T}} \mathbf{x}: \mathbf{b}^{\mathrm{T}} \mathbf{x}=M, \mathbf{0} \leq \mathbf{x} \leq \mathbf{a}\right\}$

(Wmax) $\max \left\{\mathbf{v}^{\mathrm{T}} \mathbf{x}: \mathbf{b}^{\mathrm{T}} \mathbf{x}=M, \mathbf{0} \leq \mathbf{x} \leq \mathbf{a}\right\}$

Denote the optimal value of the problem (Wmin) with $W_{1}$ and the optimal value of the problem (Wmax) with $W_{2}$. The decision maker may choose the parameter $W$ in the range $\left[W_{1}, W_{2}\right]$. Let $W \in\left[W_{1}, W_{2}\right]$. For every $t \in\{1,2, \ldots, m\}$ define the numbers

$s_{t}^{\prime}=\min \left\{\mathbf{r}_{t}^{T} \mathbf{x}: \mathbf{v}^{\mathrm{T}} \mathbf{x} \geq W, \mathbf{b}^{\mathrm{T}} \mathbf{x}=M, \mathbf{0} \leq \mathbf{x} \leq \mathbf{a}\right\}$

$s_{t}^{\prime \prime}=\max \left\{\mathbf{r}_{t}^{T} \mathbf{x}: \mathbf{v}^{\mathrm{T}} \mathbf{x} \geq W, \mathbf{b}^{\mathrm{T}} \mathbf{x}=M, \mathbf{0} \leq \mathbf{x} \leq \mathbf{a}\right\}$

The range of variation for the parameter $\tau$ is $\left[\tau_{1}, \tau_{2}\right]$ where $\tau_{1}=\min \left\{s_{t}^{\prime}: t \in\{1,2, \ldots, m\}\right\}$ and $\tau_{2}=\max \left\{s_{t}^{\prime \prime}: t \in\{1,2, \ldots, m\}\right\}$.

By introducing $m$ additional variables $y_{1}, y_{2}, \ldots, y_{m}$ one can build a linear programming problem $\left(P_{1}^{\prime \prime}\right)$ which is equivalent with the problem $\left(P_{1}^{\prime}\right)$. 


$$
\left(P_{1}^{\prime \prime}\right)\left\{\begin{array}{l}
\min \left[\sum_{t=1}^{m} y_{t}\right] \\
\tau-\mathbf{r}_{t}^{T} \mathbf{x} \leq y_{t}, t=1,2, \ldots, m \\
\mathbf{v}^{\mathrm{T}} \mathbf{x} \geq W \\
\mathbf{b}^{\mathrm{T}} \mathbf{x}=M \\
\mathbf{0} \leq \mathbf{x} \leq \mathbf{a} \\
y_{t} \geq 0, t=1,2, \ldots, m
\end{array}\right.
$$

Consider the $m$ dimensional vectors $\mathbf{e}=(1,1, \ldots, 1)$ and $\mathbf{y}=\left(y_{1}, y_{2}, \ldots, y_{m}\right)$. Then the problem $\left(P_{1}^{\prime \prime}\right)$ may be written in the vectorial form as follows:

$$
\left(P_{1}^{\prime \prime \prime}\right)\left\{\begin{array}{l}
\min \left[\mathbf{e}^{T} \mathbf{y}\right] \\
\tau \mathbf{e}-\mathbf{R x} \leq \mathbf{y} \\
\mathbf{v}^{\mathrm{T}} \mathbf{x} \geq W \\
\mathbf{b}^{\mathrm{T}} \mathbf{x}=M \\
\mathbf{0} \leq \mathbf{x} \leq \mathbf{a}, \mathbf{y} \geq 0
\end{array}\right.
$$

The maximum expected return problem

In the frame of this problem the decision maker looks for a portfolio $\mathbf{x}=\left(x_{1}, x_{2}, \ldots, x_{n}\right)$ that maximizes the expected return and satisfies the following constraints: the risk is smaller than a given limit $\rho$ and the sum invested in the portfolio of fish is equal to $M$.

$$
\left\{\begin{array}{l}
\max \boldsymbol{\mu}^{\mathrm{T}} \mathbf{x} \\
E\left[\left(\tau-\xi^{\mathrm{T}} \mathbf{x}\right)_{+}\right] \leq \rho \\
\mathbf{b}^{\mathrm{T}} \mathbf{x}=M \\
\mathbf{0} \leq \mathbf{x} \leq \mathbf{a}
\end{array}\right.
$$

As in the minimum risk problem one can define a new problem $\left(P_{2}^{\prime}\right)$ where the risk function and the expected return are replaced with some of their estimations.

$$
\left(P_{2}^{\prime}\right)\left\{\begin{array}{l}
\max \left[\mathbf{v}^{\mathrm{T}} \mathbf{x}\right] \\
\frac{1}{m} \sum_{t=1}^{m}\left(\tau-\mathbf{r}_{t}^{T} \mathbf{x}\right)_{+} \leq \rho \\
\mathbf{b}^{\mathrm{T}} \mathbf{x}=M \\
\mathbf{0} \leq \mathbf{x} \leq \mathbf{a}
\end{array}\right.
$$

For every $t \in\{1,2, \ldots, m\}$ define the numbers

$$
\begin{aligned}
& s_{t}^{\prime}=\min \left\{\mathbf{r}_{t}^{T} \mathbf{x}: \mathbf{b}^{\mathrm{T}} \mathbf{x}=M, \mathbf{0} \leq \mathbf{x} \leq \mathbf{a}\right\} \\
& s_{t}^{\prime \prime}=\max \left\{\mathbf{r}_{t}^{T} \mathbf{x}: \mathbf{b}^{\mathrm{T}} \mathbf{x}=M, \mathbf{0} \leq \mathbf{x} \leq \mathbf{a}\right\}
\end{aligned}
$$

The range of variation for the parameter $\tau$ is $\left[\tau_{1}, \tau_{2}\right]$ where $\tau_{1}=\min \left\{s_{t}^{\prime}: t \in\{1,2, \ldots, m\}\right\}$ and $\tau_{2}=\max \left\{s_{t}^{\prime \prime}: t \in\{1,2, \ldots, m\}\right\}$.

An important problem is to find the range of the parameter $\rho$. In order to find the limits of this range we shall solve the following problems

$(\rho \min ) \quad \min \left\{\frac{1}{m} \sum_{t=1}^{m}\left(\tau-\mathbf{r}_{t}^{T} \mathbf{x}\right)_{+}: \mathbf{x} \in X\right\}$

$(\rho \max ) \quad \max \left\{\frac{1}{m} \sum_{t=1}^{m}\left(\tau-\mathbf{r}_{t}^{T} \mathbf{x}\right)_{+}: \mathbf{x} \in X\right\}$

Here we denoted $X=\left\{\mathbf{b}^{\mathrm{T}} \mathbf{x}=M, \mathbf{0} \leq \mathbf{x} \leq \mathbf{a}\right\}$

Denote the optimal value of the problem ( $\rho$ min) with $\rho_{1}$ and the optimal value of the problem $(\rho \max )$ with $\rho_{2}$. The decision maker may choose the parameter $\rho$ in the range $\left[\rho_{1}, \rho_{2}\right]$.

In the case the risk map $\mathrm{R}(\mathbf{x})$ is equal to $f_{3}(\mathbf{x})$ then the maximum expected return problem is called the chance constrained problem.

The optimal trade-off problem

For every $\alpha \in[0,1]$ consider the problem

$P(\alpha): \quad \min \left\{(1-\alpha) E\left[\left(\tau-\xi^{\mathrm{T}} \mathbf{x}\right)_{+}\right]-\alpha \boldsymbol{\mu}^{T} \mathbf{x}: \mathbf{x} \in X\right\}$ Here we denoted $X=\left\{\mathbf{b}^{\mathrm{T}} \mathbf{x}=M, \mathbf{0} \leq \mathbf{x} \leq \mathbf{a}\right\}$

As in the minimum risk problem one can define a new problem $\left(P^{\prime}(\alpha)\right)$ where the risk function and the expected return are replaced with some of their estimations.

$P^{\prime}(\alpha): \min \left\{(1-\alpha) \frac{1}{m} \sum_{t=1}^{m}\left(\tau-\mathbf{r}_{t}^{T} \mathbf{x}\right)_{+}-\alpha \mathbf{v}^{T} \mathbf{x}: \mathbf{x} \in X\right\}$

Every optimal portfolio of the above problem is called an efficient portfolio.

\section{Numerical Results}

Recall the input data, the user parameters and the decision variables for the minimum risk model:

Input data:

- $\quad n$ is the number of fish species

- $\quad m$ is the number of moments for which are gathered historical data 
- The matrix $\mathbf{R}=\left(r_{t i}\right) . \quad r_{t i}$ is the market price of one $\mathrm{kg}$ of fish of species $S_{i}$ at moment $t$.

- The vector $\mathbf{a}=\left(a_{1}, a_{2}, \ldots, a_{n}\right)$ of maximum sustainable yield for the fish of species

- The vector $\mathbf{b}=\left(b_{1}, b_{2}, \ldots, b_{n}\right)$ of the fishing costs (or input costs) of fish from species

User parameters

- The sum $M$ invested in the fishing plan. The range of $M$ is the interval $\left[0, \mathbf{b}^{T} \mathbf{a}\right]$.

- The lower limit for the expected return of the fishing plan $W$. The range of $W$ is the interval $\left[W_{1}, W_{2}\right]$.

- The return target $\tau$. The range of variation for $\tau$ is the interval $\left[\tau_{1}, \tau_{2}\right]$.

Decision variables

- The fishing plan or the portfolio $\mathbf{x}=\left(x_{1}, x_{2}, \ldots, x_{n}\right)$

In this section we shall study an application of the minimum risk model for a fish farm, called Malina, located near the villages Sendreni and Smardan, Galati county, Romania. The fishery area is 131 ha and 127 ha of it are covered by water. We study 6 fish species: Carp, Sanger, Novac, Perch, Catfish, Crucian. The historical data on the fish market prices are from the period 2000-2008. They are displayed in Table 2. The sum invested in the harvest plan is $\mathrm{M}=5000 \mathrm{RON}$. As a result of computation we find $W_{1}=$ $4141.66 \mathrm{RON}, W_{2}=4394.2 \mathrm{RON}$.
Table 1. The maximum sustainable yield (MSY) and the harvesting cost for the fish species

\begin{tabular}{lcc}
\hline Fish Type & $\begin{array}{r}\text { MSY } \\
\text { in kg }\end{array}$ & $\begin{array}{r}\text { Harvesting cost } \\
\text { in RON/Kg }\end{array}$ \\
\hline Carp & 200 & 8.455 \\
Sanger & 300 & 3.680 \\
Novac & 400 & 3.680 \\
Perch & 100 & 7.500 \\
Catfish & 100 & 8.000 \\
Crucian & 500 & 2.680 \\
\hline
\end{tabular}

In the second (resp. third) column from Table 1 is displayed the vector $\mathbf{a}$ (resp. the vector $\mathbf{b}$ ).

In Table 2 are displayed the historical data on the market prices for the fish species regarding the period 2000-2008. The prices are measured in RON/kg. Table 2 can be considered as the transpose of the matrix $\mathbf{R}=\left(r_{t i}\right)$ of historical market prices.

In Table 3 (resp. in Table 4) are displayed on the columns the optimal portfolios of harvested fish for a fixed value of $W$, $W=4141.66$, (resp. $W=4192.17$ ) and various values of parameter $\tau$.

Table 2. Historical data on the market prices for the fish species (in Ron/Kg)

\begin{tabular}{lccccccccc}
\hline Fish Type & 2000 & 2001 & 2002 & 2003 & 2004 & 2005 & 2006 & 2007 & 2008 \\
\hline Carp & 6.0 & 6.0 & 6.5 & 7.0 & 7.2 & 7.5 & 8 & 8.5 & 9.0 \\
Sanger & 2.0 & 2.25 & 2.5 & 3.0 & 3.2 & 3.2 & 3.5 & 3.8 & 4.0 \\
Novac & 2.2 & 2.5 & 2.8 & 3.2 & 3.2 & 3.5 & 3.5 & 3.8 & 4.0 \\
Perch & 4.5 & 5.0 & 5.5 & 6.0 & 6.5 & 7.0 & 7.5 & 7.8 & 8.0 \\
Catfish & 6.5 & 7.0 & 7.0 & 7.5 & 7.8 & 8.0 & 8.0 & 9.0 & 9.5 \\
Crucian & 1.5 & 1.6 & 1.8 & 2.0 & 2.0 & 2.25 & 2.5 & 3.0 & 3.2 \\
\hline
\end{tabular}


Table 3. The fish harvesting portfolios for $W=4141.66$ and various values of the parameter $\tau$

\begin{tabular}{lrrrr}
\hline \multicolumn{5}{c}{$W=4141.66$} \\
\hline Carp & 103.4 & 103.4 & 200.0 & 200.0 \\
Sanger & 300.0 & 300.0 & 77.9 & 77.9 \\
Novac & 400.0 & 400.0 & 400.0 & 400.0 \\
Perch & 100.0 & 100.0 & 100.0 & 100.0 \\
Catfish & 100.0 & 100.0 & 100.0 & 100.0 \\
Crucian & 0.0 & 0.0 & 0.0 & 0.0 \\
& & & & \\
$\tau=$ & 2853.2 & 3120.8 & 3388.5 & 3656.2 \\
\hline
\end{tabular}

In Figure 1 (resp. Figure 2) is displayed the graph of the efficient frontier map associated to the minimum risk problem for $\mathrm{W}=4141.66$, (resp. $\mathrm{W}=4192.17$ ). That is to every value of
Table 4. The fish harvesting portfolios for $W=4192.17$ and various values of the parameter $\tau$

\begin{tabular}{lrrrr}
\hline \multicolumn{5}{c}{$W=4192.17$} \\
\hline Carp & 200.0 & 200.0 & 200.0 & 200.0 \\
Sanger & 295.4 & 249.0 & 77.9 & 77.9 \\
Novac & 400.0 & 400.0 & 400.0 & 400.0 \\
Perch & 100.0 & 100.0 & 100.0 & 100.0 \\
Catfish & 0.0 & 21.3 & 100.0 & 100.0 \\
Crucian & 0.0 & 0.0 & 0.0 & 0.0 \\
& & & & \\
$\tau=$ & 2904.1 & 3166.7 & 3429.3 & 3691.9 \\
\hline
\end{tabular}

the parameter $\tau$ corresponds the minimum value of the objective map (the lower partial moment of the return).

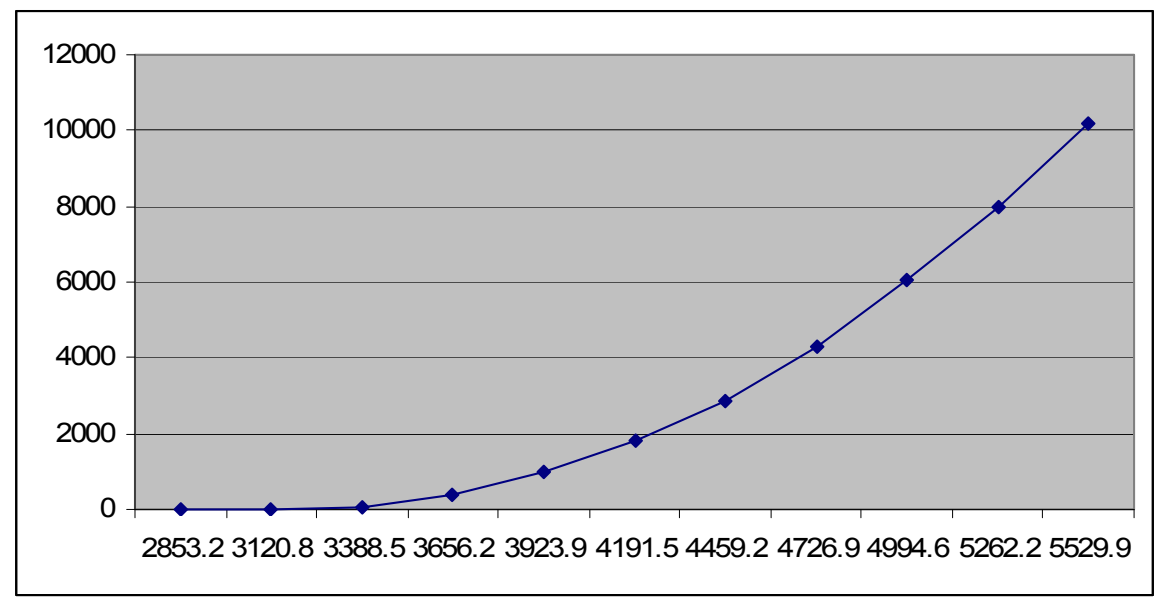

Figure 1. The efficient frontier map associated to the minimum risk problem for $W=4141.66$

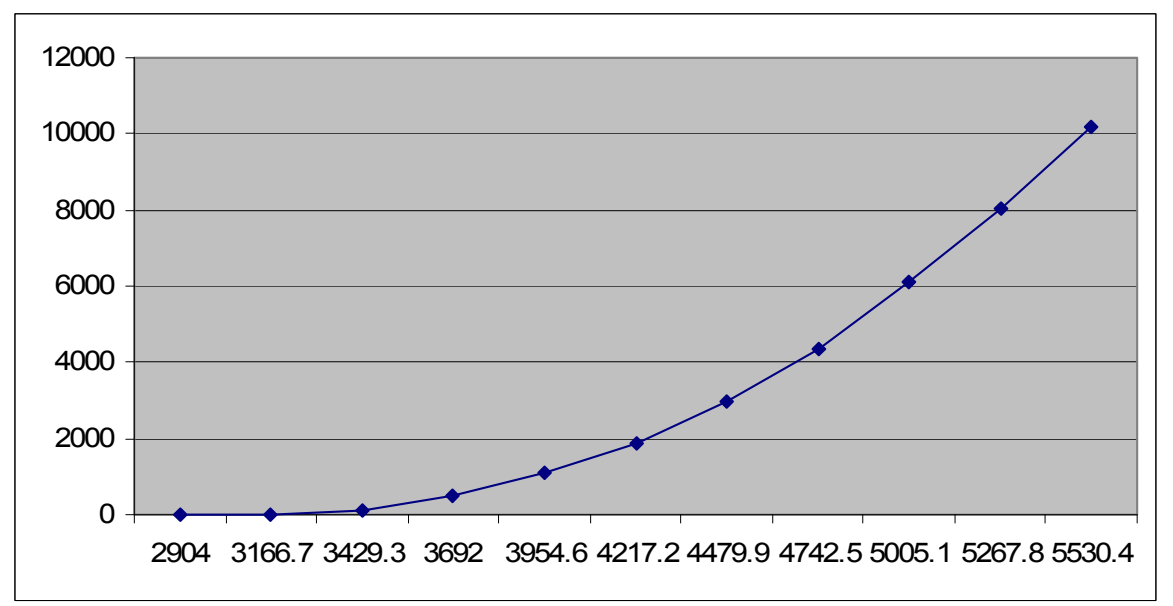

Figure 2. The efficient frontier map associated to the minimum risk problem for $W=4192.17$ 
In table 5 for each value of the parameters $\mathrm{W}$ and $\tau$ is displayed Fob, that is, the minimum value of the objective map. In Figure 3 is displayed the 3-D efficient frontier of the minimum risk problem. That is to every value of $\mathrm{W}$ and $\tau$ corresponds the minimum value of the objective map (the lower partial moment of the return). The minimum risk problem was solved for various values of the parameters $\mathrm{W}$ and $\tau$ with the MINOS solver, type NLP, from GAMS. The limits of the range of variation of the parameter $\mathrm{W}$ were obtained with the DICOPT solver, type MINLP from GAMS. Alternative solutions of the minimum risk problem may be found following the approach from Andrei [1].

In Figure 3 along the $\mathrm{x}$-axis varies the parameter $W$, along the y-axis varies parameter $\tau$ and along the vertical $\mathrm{z}$-axis varies the optimal value of the objective map.

Table 5. The values of the risk map versus the values of $W$ and $\tau$

\begin{tabular}{rrrrrrrrrrrrr}
\hline \multicolumn{1}{c}{$W=4141.66$} & $W=4192.17$ & $W=4242.68$ & $W=4293.19$ & $W=4343.7$ & & $W=4394.2$ \\
\hline \multicolumn{1}{c}{$\tau$} & Fob & $\tau$ & Fob & $\tau$ & Fob & $\tau$ & Fob & $\tau$ & Fob & $\tau$ & Fob \\
\hline 2853.6 & 0 & 2904 & 0 & 2974.9 & 0 & 3049 & 0 & 3150.4 & 0 & 3323.7 & 0 \\
3120.8 & 0 & 3166.7 & 0 & 3230.5 & 0 & 3294.3 & 0 & 3382.7 & 46.7 & 3535.6 & 199.6 \\
3388.5 & 52.5 & 3429.3 & 93.3 & 3486 & 150.0 & 3539.5 & 203.5 & 3614.9 & 318.4 & 3747.5 & 583.5 \\
3656.2 & 400.9 & 3691.9 & 472.5 & 3741.5 & 571.6 & 3784.8 & 658 & 3847.2 & 782.9 & 3959.3 & 1101.6 \\
3923.9 & 995.1 & 3954.6 & 1087.3 & 3997.1 & 1214.8 & 4030 & 1313.6 & 4079.5 & 1461.9 & 4171.2 & 1737.2 \\
4191.5 & 1798.1 & 4217.2 & 1875.2 & 4252.6 & 1981.4 & 4275.3 & 2060.6 & 4311.7 & 2206.5 & 4383 & 2491.9 \\
4459.2 & 2856 & 4479.9 & 2959.3 & 4252.6 & 3049.3 & 4520.5 & 3162.6 & 4543.9 & 3279.9 & 4594.9 & 3534.8 \\
4726.9 & 4271.7 & 4742.5 & 4365.5 & 4763.7 & 4492.4 & 4765.8 & 4504.9 & 4776.2 & 4567.8 & 4806.8 & 4751.4 \\
4994.6 & 6049.3 & 5005.1 & 6123.4 & 5019.2 & 6221.9 & 5011 & 6164.5 & 5008.5 & 6146.9 & 5018.7 & 6218.4 \\
5262.2 & 7988.9 & 5267.8 & 8033.3 & 5274.7 & 8088.9 & 5256.2 & 7941.1 & 5240.7 & 7817 & 5230.57 & 7735.7 \\
5529.9 & 10198.3 & 5530.4 & 10202.8 & 5530.3 & 10201.5 & 5501.5 & 9942.6 & 5473 & 9686.1 & 5442.4 & 9430.7 \\
\hline
\end{tabular}

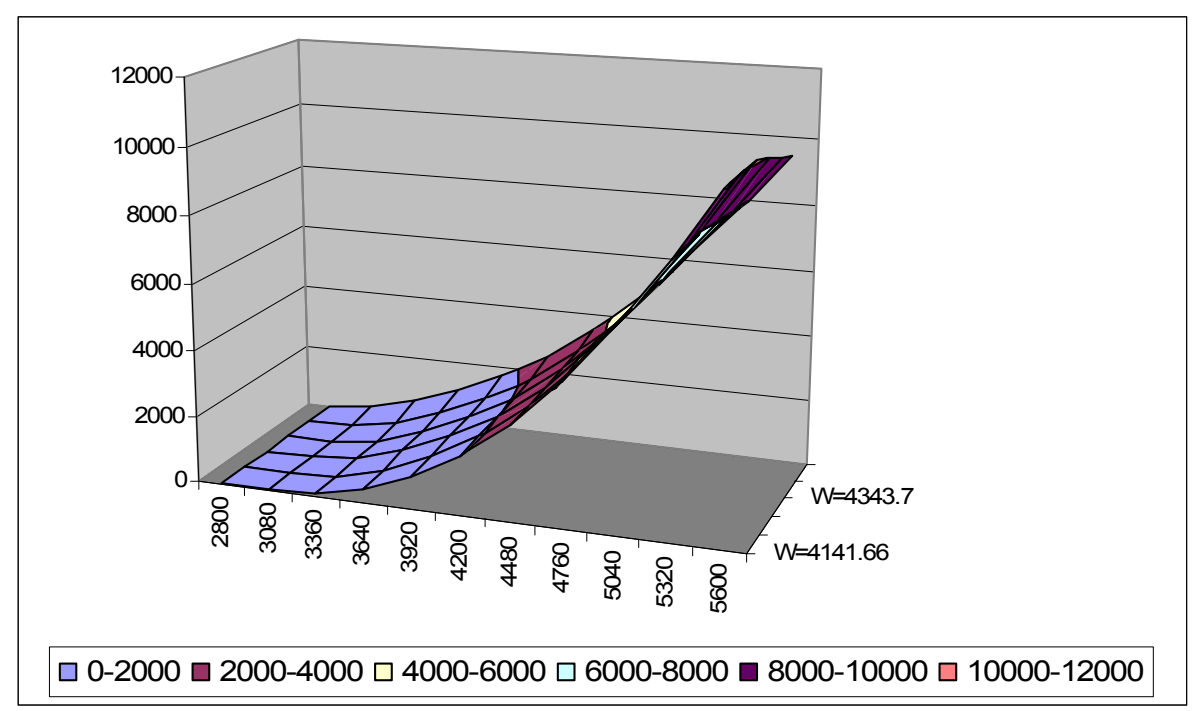

Figure 3. The 3-D efficient frontier of the minimum risk problem 


\section{Conclusions}

We presented a multi-objective portfolio selection model for fisheries management. Starting from it we defined several single objective programming problems: a minimum risk problem, a maximum expected return problem and an optimal trade-off problem. In order to facilitate the use of these models in a decision support system we gave procedures for finding the ranges of variation for the parameters. We applied the theoretical results obtained for the minimum risk model for a fish farm from Galati county. The numerical results confirm that the minimum model is a very useful tool for the management of fish farms. Several extensions of the model may be done. For example one can consider several ponds in the fish farm or one can consider the environmental impact of the fish farm and look for management solutions that meet at the same time the economic and the environmental objectives.

\section{REFERENCES}

1. ANDREI, N., On Quadratic Internal Model Principle in Mathematical Programming, Studies in Informatics and Control, Volume 18, Number 4, 2009, pp. 337-348.

2. ARNASON, R., Ecological Fisheries Management Using Individual Transferable Share Quotas, Ecological Applications 8, 1998, pp. S151-S159.

3. ARNASON, R., Fisheries Management and Operations Research, European Journal of Operational Research, Vol. 193, (3), 16 March 2009, pp. 741-751.

4. BALDURSSON, F. M., G. MAGNUSSON, Portfolio Fishing Scandinavian Journal of Economics vol. 99 (3), 1997, pp. 389-403.

5. BAZILIAN, M., F. ROQUES, Analytical Methods for Energy Diversity and Security: Portfolio Optimization in the Energy Sector: a Tribute to the Work of Dr. Shimon Awerbuch, Elsevier, 2008.

6. BJØRNDAL, T., D. E. LANE, A. WEINTRAUB, Operational Research Models and the Management of
Fisheries and Aquaculture: A review, European Journal of Operational Research, Volume 156, Issue 3, 1 August 2004, pp. 533-540.

7. BLANDON, P., Agroforestry and Portfolio Theory, Agroforestry Systems, Vol. 3, No. 3, 1985, pp. 239-249.

8. BLANK, S. C., Producers get squeezed up the Farming Food Chain: A theory of Crop Portfolio Composition and Land Use, Review of Agricultural Economics, 23, 2001, pp. 404-22.

9. EDWARDS, F. S., J. S. LINK, B. P. ROUNTREE, Portfolio Management of Wild Fish Stocks, Ecological Economics, Vol. 49, Issue 3, 1, 2004, pp. 317-329.EDWARDS, F. S., J. S. LINK, B. P. ROUNTREE, Portfolio Management of Fish Communities in Large Marine Ecosystems, Large Marine Ecosystems, Volume 13, 2005, pp. 181-199.

11. FIGGE, F., Bio-folio: Applying Portfolio Theory to Biodiversity, Biodiversity and Conservation, Vol. 13, 2004, pp. 827-849.

12. FISHER, A. C., Resource and Environmental Economics, Cambridge University Press, NY. 1981.

13. HANNA, S., Institutions for Marine Ecosystems: Economic Incentives and Fishery Management, Ecological Applications 8, 1998, pp. S170-S174.

14. HATCH, U., J. ATWOOD, A Risk Programming Model for Farm-raised Catfish, Aquaculture, Vol. 70, Issue 3, 1988, pp. 219-230.

15. HILBORN, R., J. J. MAGUIRE, A. M. PARMA, A. A. ROSENBERG, The Precautionary Approach and Risk Management: Can They Increase the Probability of Successes in Fishery Management? Canadian Journal of Fisheries and Aquatic Sciences 58, 2001, pp. 99-107.

16. KOELLNER, T., O. J. SCHMITZ, Biodiversity, Ecosystem Function, and Investment Risk, BioScience Vol. 56 No. 12, 2006, pp. 977-985. 
17. LARKIN, S., G. SYLVIA, C. TUININGA, Portfolio Analysis for Optimal Seafood Product Diversification and Resource Management, Journal of Agricultural and Resource Economics 28(2), 2003, pp. 252-271.

18. MARKOWITZ, H. M., Portfolio Selection, J. of Finance. 8, 1952, pp. 77-91.

19. PERRUSO, L., R. N. WELDON, S. L. LARKIN, Predicting Optimal Targeting Strategies in Multispecies Fisheries: A Portfolio Approach, Marine Resource Economics 20, no. 1, 2005, pp. 25-45.

20. PONTECORVO, G., Cost Benefit of Measuring Resource Variability in Large Marine Ecosystems. In Sherman K. and L.M. Alexander. Variability and Management of Large Marine Ecosystems 269-279. AAAS Selected Symposium 99. Westview Press, Boulder, Colorado 1986.

21. RĂDULESCU, M., S. RĂDULESCU, C. Z. RĂDULESCU, Mathematical Models for Optimal Asset Allocation, (Romanian). Editura Academiei, Bucuresti 2006.

22. RĂDULESCU, M., C. Z. RĂDULESCU, A Planning Model for Agricultural Production that Includes Risks Connected to Climate, Market and Environmental Constraints, (Romanian), Revista Română de Informatică şi Automatică, vol. 16, nr. 4, 2006, pp. 139-146.

23. RĂDULESCU, M., C. Z. RĂDULESCU, F. FILIP, Sustainable Production Planning Models, Proc. Romanian Academy, vol. 9, no. 2, 2008, pp. 149-156.

24. RĂDULESCU, M., C. Z. RĂDULESCU, Gh. ZBĂGANU, Asset Allocation Models in Discrete Variable, Studies in Informatics and Control, Volume 18, Number 1, 2009, pp. 63-70.

25. RĂDULESCU M., S. RĂDULESCU, C. Z. RĂDULESCU, Sustainable Production Technologies which take into Account Environmental Constraints, European Journal of Operational Research, vol. 193, no. 3, 2009, pp. 730-740.
26. REAL, L. A., Animal Choice Behavior and the Evolution of Cognitive Architecture, Science 253, 1991, pp. 980-986.

27. ROMERO, C., Una Aplicación del Modelo de Markowitz a la Selección de Planes de Variedades de Manzanos en la Provincia de Lérida, Revista de Estudios Agro-sociales, No. 97, 1976, pp. 61-79.

28. ROMERO, C., Risk Programming for Agricultural Resource Allocation: A multidimensional Risk Approach, Annals of Operations Research, Vol. 94, 2000, pp. 57-68.

29. SANCHIRICO, J. N., M. D. SMITH, D. W. LIPTON, An Empirical Approach to Ecosystem-based Fishery Management, Ecological Economics, Vol. 64, Issue 3, 15, 2008, pp. 586-596.

30. SCHNEEBERGER, M., A. E. FREEMAN, M. D. BOEHLJE, Application of Portfolio Theory to Dairy Sire Selection, J. Dairy Sci., Vol. 65, 1982, pp. 404-409.

31. SETHI, S. A., Risk Management for Fisheries, Fish and Fisheries, 2010, doi 10.1111/j.1467-2979.2010.00363.x.

32. WALTERS, C., Optimal Harvest Strategies for Salmon in Relation to Environmental Variability and Uncertain Production Parameters, Journal of the Fisheries Research Board of Canada 32, 1975, pp. 1777-1784.

33. YAnG, M. M., The Portfolio Approach for the Ecosystem-based Fishery Management, Economics Department, University of Auckland, PhD Research Proposal, April 2008. www.nzares.org.nz/pdf/A\%20Portfolio\% 20Approach.pdf 